\title{
Formação sustentável do professor no mestrado profissional
}

WAGNER RODRIGUES SILVA*

Universidade Federal de Tocantins, Palmas, TO, Brasil

\begin{abstract}
RESUMO
Esta pesquisa investigou o desafio a ser assumido pelo mestrado profissional para professores atuantes no ensino básico brasileiro, diante da demanda do mercado de trabalho pela superação de práticas acadêmicas excessivamente teóricas. A metodologia de pesquisa corresponde à análise discursiva da escrita acadêmica do professor-pesquisador e à revisão da literatura científica de diferentes disciplinas, que, por perspectivas diferenciadas, encaminham mudanças paradigmáticas na formação docente. Os resultados mostraram que a realização da pesquisa pelo professor contribui para a familiarização do profissional com letramentos necessários para mudanças nos paradigmas científico e educacional dominantes. Isso acontece em meio a disputas pela legitimação de diferentes vozes sociais representando universidade e escola. Propomos uma formação docente sustentável, orientada especialmente pela indisciplinaridade e pela legitimação de conhecimentos práticos compartilhados por professores.
\end{abstract}

PALAVRAS-CHAVE

letramento científico; letramento acadêmico; letramento do professor.

* Bolsista de Produtividade em Pesquisa do Conselho Nacional de Desenvolvimento Científico e Tecnológico (CNPq). 


\title{
SUSTAINABLE TEACHER EDUCATION IN THE PROFESSIONAL MASTERS PROGRAM
}

\begin{abstract}
This research investigated the challenge faced by the professional master's program aimed at Brazilian teachers working in basic education concerning the demand of labor market to overcome the extremely theoretical academic practices. The research methodology corresponds to discursive analyses of the teacher researcher's academic writing and to scientific literature review from different disciplines that through distinct approaches propose paradigmatic transformation in teacher education. The results showed that the development of scientific research by the teacher contributes to foster his/her familiarity with literacies required to transform the dominant scientific and educational paradigms. This fact happens within the disputes to the legitimacy of different social voices representing university and school. We propose a sustainable teacher education especially based on the antidisciplinarity and legitimacy of practical knowledges shared by teachers.
\end{abstract}

KEYWORDS

scientific literacy; academic literacy; teacher education.

\section{FORMACIÓN SOSTENIBLE DEL PROFESOR EN EL PROGRAMA DE MAESTRÍA PROFESIONAL}

\section{RESUMEN}

Este estudio investigó el reto que hay que enfrentar por la maestría profesional para profesores brasileños que trabajan en la educación básica, ante la demanda del mercado de trabajo por la superación de las prácticas académicas excesivamente teóricas. La metodología de investigación corresponde al análisis discursivo de la escrita académica del profesor-investigador y a la revisión de la literatura científica de distintas disciplinas que, por perspectivas diferentes, proponen cambios paradigmáticos en la formación del profesor. Los resultados mostraron que el desarrollo de la investigación por el profesor contribuye para la familiarización del profesional con alfabetizaciones necesarias para los cambios en los paradigmas científico y educacional dominantes. Esto ocurre en medio de las disputas pela legitimación de diferentes voces sociales representando universidad y escuela. Proponemos una formación docente sostenible, orientada por la indisciplinaridad y por la legitimación de conocimientos prácticos compartidos por los profesores.

\section{PALABRAS CLAVE}

literacidad científica; literacidad académica; literacidad docente. 


\section{INTRODUÇÃO}

Neste artigo, reunimos questões teóricas e práticas concebidas como desafiadoras no complexo contexto brasileiro de formação continuada do professor de Língua Portuguesa, o que não desautoriza o leitor a articulá-las à formação de professores de outras disciplinas escolares. As questões são focalizadas por meio da seguinte pergunta norteadora desta investigação: que contribuições a universidade pode oferecer para a formação sustentável do professor de língua materna, orientada pela prática de pesquisa científica na escola básica brasileira?

Apresentamos uma pergunta bastante ampla que não se esgotará neste texto. Delimitamos a investigação à proposta de formação docente com base no Programa de Mestrado Profissional em Letras (ProfLetras) aprovado para funcionamento em rede pela Coordenação de Aperfeiçoamento de Pessoal de Nível Superior (CAPES), reunindo, no último processo seletivo, 49 unidades de ensino em instituições públicas de ensino superior nas cinco regiões brasileiras ${ }^{1}$. $\mathrm{Na}$ base da profissionalidade do professor de Língua Portuguesa, há demanda pela formação sustentável atrelada à maior familiarização docente com diferentes práticas de letramento, tematizadas nesta pesquisa mediante as noções teóricas de letramento científico, letramento acadêmico e letramento do professor, úteis para mediar o trabalho de formação continuada.

Numa perspectiva indisciplinar, utilizamos referenciais teórico-metodológicos de origens diversas, o que é justificado pela complexidade do objeto de investigação construído. Focalizar a formação continuada do professor sem perder de vista o campo de forças que circunda os pontos de contato entre universidade e escola inevitavelmente demanda a interação com referenciais diversos, mesmo que estejamos lidando diretamente com o professor de uma disciplina escolar específica. Nesses pontos, por exemplo, a disputa de saberes mediadores da ação profissional é o resultado do fervilhar das forças diretamente atreladas à negociação de identidades profissionais (professor/pesquisador/objeto pesquisado/colaborador/participante).

Discretizamos contribuições teóricas originárias de diferentes perspectivas de estudos do letramento, passíveis de orientação do trabalho do professor de Língua Portuguesa, além de descrever o contexto de formação focalizado nesta investigação. Utilizamos pesquisas desenvolvidas nas áreas de ciência da educação (Castro, 2005; Lüdke; Boing, 2012; Nóvoa, 2007; Zeichner; Diniz-Pereira, 2005), ciências sociais (Bourdieu, 2004; 2001; Sousa Santos, 2007; 1995) e linguística aplicada (Fiad, 2011; Fischer, 2008; Kleiman, 2014; 2001). Utilizamos ainda estudos que, pela própria natureza não disciplinar, não são enquadrados em disciplinas específicas (Athayde et al., 2013; Rabelo et al., 2013; Rattner, 1999; Santos, 2007).

Este artigo é composto de quatro partes principais, além desta introdução, das considerações finais e das referências. Em "Demanda do mestrado profissional para professor”, caracterizamos o modelo de mestrado profissional brasileiro construído

1 Refiro-me aqui ao Edital n. ${ }^{\circ}$ 001/2015 - Exame Nacional de Acesso ao Mestrado Profissional em Letras —, sob a responsabilidade da Universidade Federal do Rio Grande do Norte (UFRN), unidade sede do programa profissional. No referido edital, foram ofertadas 834 vagas distribuídas para as cinco regiões geográficas brasileiras. 
em resposta ao espaço deixado no mercado de trabalho pela formação acadêmica estritamente teórica. Em "Universidade e escola: um campo em disputa", descrevemos algumas forças em disputa no espaço social instaurado entre universidade e escola por intermédio do reingresso do professor na primeira instituição mencionada. Em "Letramentos necessários à formação profissional”, pontuamos algumas contribuições de diferentes perspectivas de estudo do letramento para a formação sustentánvel do professor no mestrado profissional. Finalmente, em "Vozes em conflito: letramentos em construção", exemplificamos o conflito de vozes representativas das instituições de ensino focalizadas, no processo de familiarização do professor com letramentos necessários para o exercício mais produtivo da pesquisa científica na escola básica.

\section{DEMANDA DO MESTRADO PROFISSIONAL PARA PROFESSOR}

A criação do ProfLetras pode se configurar como uma resposta para uma antiga demanda na formação do professor de Língua Portuguesa para o contexto brasileiro da escola básica. Num estudo realizado por Castro (2005) sobre a demanda da sociedade brasileira por profissionais preparados para gerar respostas mais imediatas para o avanço de setores da economia e sociais, o autor destaca o mestrado profissional (MP) para formar professores como "o caso superespecial" e "a área que deverá receber mais atenção e apoio nos mestrados profissionais"(p. 22). Ainda nos termos do autor,

é dramática a escassez de professores de bom nível, em todos os níveis e em todos os azimutes do mapa do Brasil. E como não há bom ensino sem bons professores, se há uma prioridade mais prioritária para a CAPES é a formação de professores (Castro, 2005, p. 22).

O MP para professor caracteriza-se como uma resposta aos resultados negativos já conhecidos da formação inicial nas licenciaturas, vítimas do teoricismo que mantém o distanciamento entre os conhecimentos produzidos na universidade e a prática efetiva do magistério nas escolas básicas. A escassez de "professores de bom nível", de que fala Castro (2005), pode ser explicada, de alguma forma, pelo pouco preparo desses profissionais para lidar com as demandas pedagógicas contemporâneas do local de trabalho. Retornamos para o distanciamento entre universidade e escola básica.

$\mathrm{Na}$ ciência da educação, o diagnóstico negativo da formação inicial do professor tem sido anunciado com frequência em diferentes países. No território brasileiro, Lüdke e Boing (2012, p. 430) afirmam estarem

convencidos de que a preparação de futuros professores, hoje sob a responsabilidade das universidades, sofre, de fato, uma carência no lado das práticas, estando essas instituições muito mais preocupadas com a formação no lado teórico.

No contexto americano, Zeichner, Payne e Brayko (2014, p. 2) destacam que, mesmo na atual era da colaboração entre universidade e escola, a primeira mantém a hegemonia sobre a construção e disseminação do conhecimento a respeito do ensino demandado na formação do professor, ao passo que a segunda continua 
na posição de "campos da prática", em que o professor em formação inicial testa práticas propostas pela universidade.

Em resposta a esse distanciamento da prática na formação docente, independentemente do momento em que ocorra essa instrução, Nóvoa (2007, p. 14), no contexto português, tem insistindo numa "formação mais centrada nas práticas e na análise das práticas":

A formação do professor é, por vezes, excessivamente teórica, outras vezes excessivamente metodológica, mas há um déficit de práticas, de refletir sobre as práticas, de trabalhar sobre as práticas, de saber como fazer. É desesperante ver certos professores que têm genuinamente uma enorme vontade de fazer de outro modo e não sabem como. Têm o corpo e a cabeça cheios de teoria, de livros, de teses, de autores, mas não sabem como aquilo tudo se transforma em prática, como aquilo tudo se organiza numa prática coerente.

Esse contexto adverso motiva a intervenção de agentes governamentais com a proposta de MP para professor, não significando a desistência da licenciatura ${ }^{2}$. Conforme será discutido na seção seguinte deste artigo, o teoricismo ou o academicismo não estão restritos ao campo do magistério. Ambos perpassam a prática científica em todas as áreas do conhecimento, daí a existência de uma "dívida social" a ser resgatada pelas universidades, no termo utilizado por Ribeiro $(2005$, p. 9$)$ ao focalizar a política da CAPES para os MP. A respeito do papel social das ciências humanas e sociais, em que estamos situados, Ribeiro $(2005$, p. 9) destaca que, embora sejam, por definição, as mais adequadas "para contribuírem à melhora de nossos indicadores sociais", elas fecham-se no mundo universitário e não transferem, "para aqueles que de fato agem no mundo da prática, os meios mais novos e aptos a lutar contra a miséria e a iniquidade" (Ribeiro, 2005, p. 9). A sustentabilidade demanda a efetiva transferência de conhecimento para o local de trabalho.

Nessa perspectiva, as palavras de Castro (2005) sintetizam dois mercados de trabalho descobertos pelas pós-graduações acadêmicas brasileiras: especialização (ES), mestrado acadêmico (MA) e doutorado acadêmico (DA). Esses mercados devem ser preenchidos pelo curso stricto sensu profissional. A síntese é ilustrativa dos estudos de Quelhas, Faria Filho e França (2005) e Ribeiro (2005), com os quais dialogamos a respeito do MP.

1. O mercado das empresas que necessitam de pessoal com nível de preparação que ultrapassa a graduação; 2 . As instituições de ensino que precisam de perfis de professores diferentes dos mestres e doutores voltados para a pesquisa acadêmica (CASTRO, 2005, p. 16).

2 Lembramos aqui da existência do Programa de Consolidação das Licenciaturas (Prodocência) e do Programa Institucional de Bolsa de Iniciação à Docência (PIBID), ambos coordenados pela CAPES dentro dos programas de fortalecimento da formação inicial do professor, os quais trazem como principal objetivo a inserção do acadêmico na prática pedagógica em escolas básicas. 
O segundo mercado, instituições de ensino, interessa-nos mais de perto, especialmente no tocante às instituições de ensino básico. Nesse sentido, o objetivo do ProfLetras está bem definido no edital de seleção: "Capacitar professores de Língua Portuguesa para o exercício da docência no Ensino Fundamental, com intuito de contribuir para a melhoria da qualidade do ensino no país" (Edital n. ${ }^{\circ}$ 001/2015, p. 1) $)^{3}$.

Lamentavelmente, o projeto do ProfLetras deixa de lado o professor apenas licenciado em Pedagogia atuante na educação infantil e no ensino fundamental I, o qual é responsável pela alfabetização das nossas crianças e pela disciplina de Língua Portuguesa. Provavelmente, esse profissional passou por uma formação ainda mais generalista na licenciatura em Pedagogia. Nos termos de Lüdke e Boing (2012, p. 443), as licenciaturas, que assumiram para si a formação profissional, têm sido acusadas "de academicismo e falta de atenção à preparação" do professor "para o trabalho real". Eis o perfil do candidato ao ProfLetras contemplado no último processo seletivo nacional:

\section{II - DOS REQUISITOS}

2.1. Poderão participar do Exame Nacional de Acesso candidatos que atendam às seguintes situações:

a) Ser portador de diploma de curso superior de Licenciatura em Letras, habilitação português, devidamente registrado no Ministério da Educação;

b) Ser professor de Língua Portuguesa do Ensino Fundamental (1. ${ }^{\circ}$ ao $9 .^{\circ}$ anos), em Escola da Rede Pública de Ensino do Brasil, regularmente admitido e pertencente ao quadro permanente de servidores; e

c) Estar ministrando aula de Língua Portuguesa em qualquer ano do Ensino Fundamental (1..$^{\circ}$ ao $9 .^{\circ}$ anos). (Edital n. $.^{\circ} 001 / 2015$, p. 1; itálico do original).

Apresentamos adiante um quadro expositivo com alguns desafios bastante significativos para a formação continuada de professores no ProfLetras, ainda que nem todos os excertos selecionados tenham sido originalmente enunciados a respeito do MP para professor. Os excertos foram reproduzidos de alguns estudos reunidos

3 No portal da CAPES, encontramos o seguinte desafio resumido trazido para o ProfLetras: "Considerando as múltiplas tendências teórico-metodológicas e uma perspectiva fortemente transdisciplinar, o ProfLetras busca formar professores de língua portuguesa voltados para a inovação na sala de aula, ao mesmo tempo que, de forma crítica e responsável, possam refletir acerca de questões relevantes sobre diferentes usos da linguagem presentes contemporaneamente na sociedade. Esse professor precisará responder aos desafios educacionais do Brasil contemporâneo, considerando princípios fundamentais da construção de uma educação linguística que vise a práticas sociais mediadas pela linguagem" (disponível em: <http://www.capes.gov.br/educacao-a-distancia/profletras>. Acesso em: 25 de julho de 2015). 
no volume temático sobre MP da Revista Brasileira de Pós-Graduação, mantida pela CAPES (Castro, 2005; Quelhas; Faria Filho; França, 2005; Ribeiro, 2005).

Conforme demonstramos no Quadro 1, o MP tem metas a serem alcançadas e não pode ser concebido como um curso de categoria inferior (2) quando comparado ao MA ou DA, que, por não conseguirem responder a anseios específicos do mercado profissinal, têm seu escopo restrito à formação de pesquisadores altamente capacitados para a produção de tecnologias inovadoras e para a formação de novos pesquisadores, realimentando o quadro de especialistas atuantes em diferentes instituições de pesquisa científica.

Considerando que o MP é um "mestrado para quem trabalha" (1), a "experiência profissional" (3) dos professores precisa ser valorizada. Esforços precisam ser empregados para que se multipliquem os pontos de contato entre universidade e

\section{Quadro 1-Desafios para o MP.}

\begin{tabular}{|c|c|}
\hline 1. & $\begin{array}{l}\text { "O mestrado profissional é, sobretudo, voltado para profissionais que querem } \\
\text { avançar seus conhecimentos, sejam funcionários de empresa sejam professores. } \\
\text { Ou seja, é um mestrado para quem trabalha” (Castro, 2005, p. 19). }\end{array}$ \\
\hline 2. & $\begin{array}{l}\text { "O que está freando o desenvolvimento do mestrado profissional é a sua estrutura atrelada } \\
\text { à [pós-graduação] PG acadêmica que lhe tira a vida própria e os converte em prêmios de } \\
\text { consolação ou mendigos, no Olimpo dos cursos acadêmicos"(Castro, 2005, p. 17). }\end{array}$ \\
\hline 3. & $\begin{array}{l}\text { "O que se requer é ação. Sem valorizar a experiência profissional, matamos no } \\
\text { nascedouro qualquer chance de êxito de tais mestrados" (Castro, 2005, p. 18). }\end{array}$ \\
\hline 4. & $\begin{array}{l}\text { "Daí que seja preocupante as ciências que se preocupam com a sociedade, muitas vezes, } \\
\text { não participarem do debate sobre como o conhecimento mais qualificado será aplicado } \\
\text { socialmente. Daí, o empenho da CAPES em facilitar, às distintas áreas do conhecimento, } \\
\text { sua aplicação prática para além dos muros da academia" (Ribeiro, 2005, p. 11). }\end{array}$ \\
\hline 5. & $\begin{array}{l}\text { "No MA, pretende-se pela imersão na pesquisa formar, a longo prazo, um pesquisador. } \\
\text { No MP também deve ocorrer a imersão na pesquisa, mas o objetivo é formar } \\
\text { alguém que, no mundo profissional externo à academia, saiba localizar, reconhecer, } \\
\text { identificar e, sobretudo, utilizar a pesquisa de modo a agregar valor a suas atividades, } \\
\text { sejam essas de interesses mais pessoal ou mais social" (Ribeiro, 2005, p. 15). }\end{array}$ \\
\hline 6. & $\begin{array}{l}\text { "É particularmente importante o trabalho de conclusão ou os trabalhos realizados } \\
\text { ao longo do curso, que preferencialmente devem constituir casos de conhecimento } \\
\text { científico ao ambiente profissional para o qual se volta o MP. Isso será tanto } \\
\text { melhor se parte, pelo menos, do corpo docente demonstrar produção em campos } \\
\text { aplicados no referido ambiente profissional" (Ribeiro, 2005, p. 15). } \\
\end{array}$ \\
\hline 7. & $\begin{array}{l}\text { "Dessa forma, o curso busca formar um profissional capacitado para pesquisa, } \\
\text { desenvolvimento e inovação (P\&D\&I), e também capaz de atuar como } \\
\text { multiplicador, repassando seus conhecimentos para os demais profissionais do } \\
\text { seu campo profissional" (Quelhas; Faria Filho; França, 2005, p. 98). }\end{array}$ \\
\hline 8. & $\begin{array}{l}\text { "À universidade, depositário do conhecimento produzido em vários campos, caberia } \\
\text { não só buscar, mas também identificar problemas e questões, como colocar seu } \\
\text { conhecimento à disposição dos mestrandos inscritos no mestrado profissional, orientando- } \\
\text { os na busca dos equacionamentos esperados. Esse, por definição, seria o mestrado } \\
\text { profissional, distinguindo-se igualmente da especialização e do mestrado voltado à } \\
\text { formação de natureza acadêmica" (Quelhas; Faria Filho; França, 2005, p. 99). }\end{array}$ \\
\hline
\end{tabular}


escola, na perspectiva da construção sustentável do conhecimento científico, eliminando o descarte da experiência docente por parte da academia, que tende a insistir na autossuficiência para a produção de conhecimento. Ao defenderem a proposta de pesquisa-ação para a formação de professores, conforme detalhamos no fim deste artigo, Zeichner e Diniz-Pereira (2005, p. 66) afirmam que "não podemos confiar apenas no conhecimento gerado na universidade para a formação profissional e melhoria institucional". Os autores acrescentam ainda que "há muito o que aprender das teorias geradas na universidade, mas esse discurso externo deve ser de alguma forma integrado a um processo de pesquisa que é desenvolvido a partir da prática" (Zeichner e Diniz-Pereira, 2005, p. 66).

A cooperação, a compaixão e a solidariedade são valores vitais para a interação sustentável e precisam estar presentes nas práticas acadêmicas do mestrado para professor (Rattner, 1999). Nessa perspectiva, compreendemos sustentabilidade como:

o princípio estruturador de um processo de desenvolvimento centrado nas pessoas e que poderia se tornar o fator mobilizador e motivador nos esforços da sociedade para transformar as instituições sociais, os padrões de comportamento e os valores dominantes (Rattner, 1999, p. 233).

O MP precisa proporcionar a construção coletiva de saberes, possibilitando a "aplicação prática para além dos muros da academia"(4), rompendo com a reprodução acrítica de teorias ou com a prática de pesquisa em função do fortalecimento ou da confirmação de teorias de referência. Conforme afirmam Zeichner e DinizPereira (2005, p. 71), "com raríssimas exceções, a pesquisa educacional brasileira está, sem dúvida alguma, concentrada nas universidades”. Para haver produção de conhecimento sustentável, o professor precisa se familiarizar com a prática de pesquisa (5), o que até aqui parece se estagnar na retórica de cobrança pela academia, que há algum tempo já anunciou a necessidade da formação do professor reflexivo, ignorando muitas vezes o paradoxo aí existente a ser combatido coletivamente pela comunidade escolar, como destaca Nóvoa $(2007$, p. 12)

há um paradoxo entre a retórica do professor reflexivo e, ao mesmo tempo, a inexistência de condições de trabalho concretas - desde condições de tempo, a matéria prima mais importante da reflexão - e desenvolvimento profissional que possam, de fato, alimentar a idéia do professor reflexivo.

Por outro lado, o efeito retroativo do ProfLetras para renovação das próprias práticas acadêmicas, especialmente para a do formador, pode ser bastante

4 Sobre as condições adversas para o professor brasileiro agregar a prática da pesquisa às atividades do magistério, Zeichner e Diniz-Pereira (2005, p. 71) salientam que, "apesar de haver parcerias entre universidades e Secretarias de Educação para o desenvolvimento de programas de formação continuada que incluam a realização de pesquisas por parte dos professores, as condições de trabalho da maioria dos educadores são tão precárias que às vezes pode parecer piada de mau gosto falar em pesquisas desenvolvidas por professores na escola". 
relevante. Diferentemente dos alunos da licenciatura, os professores trazem inúmeras experiências e saberes construídos na escola básica, os quais são elementos diferenciadores para a produção cooperativa de "pesquisa, desenvolvimento e inovação (P\&D\&I)" (7) a serem utilizados em aulas de Língua Portuguesa no ensino básico e, inclusive, na formação inicial de professores nas licenciaturas. Não só os professores, mas também os formadores podem ser multiplicadores (7), em seus locais de trabalho, de novas experiências e saberes construídos em pontos de contato mais fortalecidos.

Uma ameaça ao ProfLetras é a reprodução de práticas características da pós-graduação acadêmica por parte dos docentes do programa, a exemplo das exaustivas atividades escritas de revisão da literatura de referência exigidas dos alunos sem "equacionamentos esperados" (8) em virtude das demandas da escola básica. Por essa razão, Ribeiro (2005, p. 15) destaca a relevância do corpo docente do MP de "demonstrar produção em campos aplicados no referido ambiente profissional" (6). No campo dos estudos da linguagem, o trabalho desenvolvido por linguistas aplicados pode contribuir de forma bastante efetiva com o mestrado para professor. Castro (2004, p. 23, itálico do original) pontua três perfis profissionais para compor o corpo docente do MP:

São necessários os mais acadêmicos, com seus conhecimentos teóricos mais profundos. Devem também haver alguns poucos que possam ensinar uma didática aplicada. E, mais importante, deve haver muitos professores que sejam os super-teachers em sala de aula. O centro da gravidade do curso deve estar pendendo em direção ao último grupo.

Conforme evidente na última citação, o autor destaca a importância da composição do corpo docente do MP por profissionais com excelente reconhecimento de sua atuação profissional no local de trabalho de origem do aluno do referido curso (super-teachers). Mesmo merecendo um estudo à parte, essa composição não é experienciada no ProfLetras. Provavelmente, o formador responsável pelo estágio supervisionado da licenciatura atua mais proximamente da escola de educação básica e pode contribuir de forma bastante efetiva para o MP. Nos termos de Castro (2004,p. 18), "os professores acadêmicos tem que estar presentes, pois há disciplinas acadêmicas nos mestrados profissionais. Mas não podem mandar demais. Se isso acontecer, voltamos à estaca zero da mímica ao mestrado acadêmico”.

Destacamos a necessidade de professor e formador realizarem questionamentos contínuos a respeito da produtividade do mestrado para professores diante das demandas locais para o ensino de Língua Portuguesa. Talvez, o modelo vigente ainda não seja o esperado, mas pode ser o possível diante das forças em disputa no encontro entre universidade e escola, que passamos a tematizar na seção seguinte.

\section{UNIVERSIDADE E ESCOLA: UM CAMPO EM DISPUTA}

O fantasma do teoricismo ou academicismo que insiste em pairar sobre a prática acadêmica de formação de professores está atrelado à compreensão ainda bastante compartilhada na academia sobre produção do conhecimento científi- 
co na denominada ciência moderna ${ }^{5}$ (Latour, 1994; Sousa Santos, 2007; 1995). Não aprofundamos a discussão sobre os paradigmas investigativos dominante e emergente, constantemente em disputa diante de problemas sociais que não mais sustentam respostas superficiais ou fragmentadas quando apreendidos como objetos de investigação científica. Nosso enfoque recai sobre as prováveis implicações desses paradigmas para o trabalho de formação no ProfLetras, pois eles orientam igualmente as práticas de ensino em diferentes níveis de instrução.

Os conhecimentos teóricos orientadores da formação do professor de Língua Portuguesa não podem se limitar aos saberes produzidos exclusivamente no campo dos estudos da linguagem. Nas aulas de qualquer disciplina escolar, há diferentes atores sociais em interação que precisam ser visibilizados. Para tanto, os atores sociais demandam tratamento epistemológico diferenciado. Insistir na disciplinarização significa acreditar, por exemplo, que uma produtiva aula de produção textual oral depende exclusivamente de fundamentação nos estudos linguísticos.

A perspectiva do desenvolvimento sustentável na formação docente demanda um paradigma inovador de educação, de modo que academia e sociedade construam conjuntamente conhecimentos legitimados. Nos termos de Athayde et al. (2013, p. 732), esse paradigma "subentende um processo de transformação do saber que se contrapõe à racionalidade científica baseada em modelos reducionistas e fragmentados, fomentando a construção de um conhecimento interdisciplinar e integrativo”.

Ao relatarem uma experiência produtiva numa pós-graduação acadêmica interdisciplinar orientada por valores de sustentabilidade, Rabelo et al. (2013, p. 642) também contrapõem o modelo de formação inovador proposto ao paradigma da ciência moderna, fundamentado em preceitos positivistas que foram necessários "para um conhecimento e avanço tecnológico especializado", mesmo deixando "como legado uma cegueira disciplinar, advinda da fragmentação do saber e impotente diante de problemas acentuados ou gerados pelo progresso".

Supervalorizando o conhecimento disciplinar, a ciência moderna legitima a universidade como espaço privilegiado de construção do conhecimento válido, contribuindo para a manutenção do que Sousa Santos (2007, p. 72) denomina de "pensamento abissal", caracterizado "pela capacidade de produzir e radicalizar distinções", a exemplo dos seguintes pares opositivos constitutivos do paradigma dominante: observador/observado; subjetivo/objetivo; coletivo/individual.

Quando assumimos tais pares opositivos como orientação para a prática científica, trabalhamos com a ilusão do observador distanciado do objeto ou sujeito

5 Conforme Sousa Santos (1995, p. 15), "na ciência moderna o conhecimento avança pela especialização. O conhecimento é tanto mais rigoroso quanto mais restrito é o objeto sobre que incide. Nisso reside, aliás, o que hoje se reconhece ser o dilema básico da ciência moderna: o seu rigor aumenta na proporção directa da arbitrariedade com que espartilha o real. Sendo um conhecimento disciplinar, tende a ser um conhecimento disciplinado, isto é, segrega uma organização do saber orientada para policiar as fronteiras entre as disciplinas e reprimir os que as quiserem transpor. É hoje reconhecido que a excessiva parcelização e disciplinarização do saber científico faz do cientista um ignorante especializado e que isso acarreta efeitos negativos". 
de pesquisa. Numa investigação desenvolvida em sala de aula, por exemplo, o pesquisador seria autossuficiente para depreender rigorosamente a verdade inscrita nos dados coletados, independentemente da compreensão dos sujeitos investigados, os quais, por outro lado, poderiam ser mais bem integrados à pesquisa se exercessem funções de colaboradores ou participantes com papéis claramente negociados. Esse procedimento reducionista contrapõe-se à prática investigativa sustentável, na qual se legitima o trabalho científico cooperativo em função de interesses compartilhados pelos atores sociais envolvidos.

$\mathrm{Na}$ Figura 1, representamos o campo de forças em disputa instaurado em espaços sociais de formação continuada do professor do tipo observável no ProfLetras. Esse campo de força não existe necessariamente de forma física, mas informa nossos pensamentos e modos de agir enquanto atores sociais. Trata-se de uma representação inspirada em teorias produzidas nas ciências sociais, em função da apreensão de posições ocupadas por atores sociais conforme diferentes capitais compartilhados em lugares e em momentos pontuais (Bourdieu, 2004; 2001; Sousa Santos, 2007).

Os pontilhados utilizados na Figura 1 representam forças em disputa no contexto de formação continuada do professor. Trata-se de um cenârio dinâmico, dada a constante interação entre diversos atores sociais, apesar da disposição espacial determinada pelo que Bourdieu (2004; 2001) denomina de capital simbólico, ao fazer referência a bens socialmente legitimados em função da manutenção ou reprodução de uma ordem espacial e social.

No primeiro momento da representação, identificado pela letra A, encontramos fronteiras estabelecidas entre universidade e escola com base nos conhecimentos teóricos e práticos valorizados, respectivamente, em cada uma dessas instituições. Na sociedade letrada em que estamos inseridos, as teorias acadêmicas

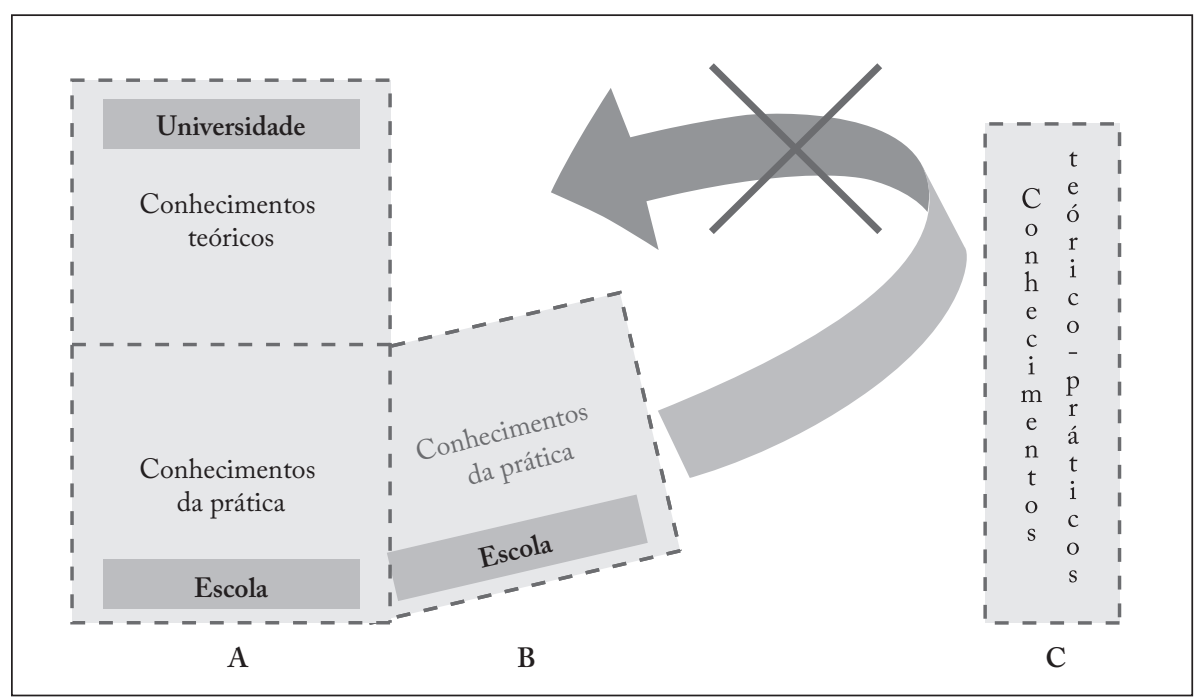

Figura 1 - Campo de forças. 
são mercadorias supervalorizadas quando comparadas aos conhecimentos da prática pedagógica produzidos entre profissionais da educação no exercício diário do trabalho pedagógico.

Esse desequilíbrio no mercado de conhecimentos pode ser justificado pela perspectiva dos estudos do letramento, que investigam diferentes maneiras como a escrita afeta as relações interpessoais em nossa sociedade grafocêntrica (Barton; Papen, 2010; Kleiman; Dos Santos, 2014). O paradigma dominante ilustra o tipo de mito sustentado pelo pensamento ocidental e eurocêntrico que legitima a produção científica do "Norte global", onde está situado o "mundo civilizado", contraposto ao "mundo colonizado", nos termos de Sousa Santos (2007)6.

A lógica do pensamento abissal é a mesma que orienta as forças em disputa no contexto da formação continuada do professor. A visibilidade do conhecimento científico assenta na desconsideração do conhecimento das pessoas comuns, como os "conhecimentos populares, leigos, plebeus, camponeses ou indígenas" (Sousa Santos, 2007, p. 72). Desse lado invisibilizado da linha, encontram-se os conhecimentos práticos partilhados por professores. Nos termos de Sousa Santos (2007, p. 73), no lado da invisibilização, "não há conhecimento real; existem crenças, opiniões, magia, idolatria, entendimentos intuitivos ou subjetivos, que na melhor das hipóteses podem se tornar objeto ou matéria-prima de investigações científicas”.

Ainda no tocante à Figura 1 , a letra $\mathrm{B}$ representa o risco de os alunos do ProfLetras reproduzirem as vozes acadêmicas ao se apropriarem das práticas dominantes do letramento acadêmico e do letramento científico. Nesse sentido, universidade e escola perdem a oportunidade de construir de forma colaborativa e, portanto, sustentável, conhecimentos que possam incidir diretamente sobre as aulas de Língua Portuguesa na escola básica. A prática colaborativa seria um terceiro espaço, representado pela letra $\mathrm{C}$, e resultaria em algo do tipo conhecimento teórico-prático.

$\mathrm{Na}$ seção seguinte, revisitamos alguns estudos do letramento pelas demandas existentes para a formação sustentável do professor no MP. Pontuamos algumas contribuições teórico-práticas originárias desses estudos.

\section{LETRAMENTOS NECESSÁRIOS À FORMAÇÃO PROFISSIONAL}

$\mathrm{O}$ alcance de contribuições das pesquisas sobre a escrita para compreensão da vida e das instituições contemporâneas justifica o interesse de diferentes disciplinas

6 De acordo com Sousa Santos (2007, p. 79), “o pensamento moderno ocidental é um pensamento abissal. Consiste em um sistema de distinções visíveis e invisíveis, sendo que estas últimas fundamentam as primeiras. As distinções invisíveis são estabelecidas por meio de linhas radicais que dividem a realidade social em dois universos distintos: o ‘deste lado da linha' e o 'do outro lado da linha'. A divisão é tal que 'o outro lado da linha' desaparece como realidade, torna-se inexistente e é mesmo produzido como inexistente. Inexistência significa não existir sob qualquer modo de ser relevante e compreensível. Tudo aquilo que é produzido como inexistente é excluído de forma radical porque permanece exterior ao universo que a própria concepção de inclusão considera como 'o outro'. A característica fundamental do pensamento abissal é a impossibilidade da co-presença dos dois lados da linha”. 
ou campos do conhecimento em estudar o fenômeno do letramento (Barton; Papen, 2010). Esse alcance explica ainda o enfoque não disciplinar demandado pelo objeto de pesquisa e as subcategorizações do fênomeno motivadas por interesses investigativos diversos, como as noções focalizadas de letramento científico, letramento acadêmico e letramento do professor.

O próprio percurso investigativo orientador deste estudo ilustra a abordagem indisciplinar característica dos estudos do letramento. Insistimos em afirmar que atribuir ao professor a responsabilidade pelos resultados indesejados produzidos na escola básica é um contrassenso. Essa atitude corresponde à reprodução de discursos preconceituosos a respeito do letramento do professor. Esses discursos não estão ancorados na ampla observação do espaço social em que se instauram, minimamente, a formação e a atuação profissional do professor. Investigar as forças em disputa no contexto da formação do MP informadas pela tradição do paradigma científico dominante a ser combatido significa visibilizar uma das causas, não menos relevante que outras, do complexo desafio enfrentado em função do empoderamento do professor.

Os estudos do letramento científico desenvolvidos no campo interdisciplinar do ensino de ciências ajudam-nos a compreender a relevância da maior familiarização do professor com práticas de investigação científica que possam auxiliá-lo na prevenção, identificação e solução de problemas que atinjam o seu local de trabalho. Conforme Santos (2007, p. 478), o letramento científico demanda do cidadão a compreensão do conteúdo científico, envolvendo aí o próprio discernimento do que é ciência e de práticas caracterizadoras do fazer científico, além da função social da ciência, ou seja, o discernimento dos riscos e benefícios das atividades científicas.

Esse enfoque crítico do letramento científico parece fora da agenda brasileira das investigações científicas sobre educação linguística na escola básica. Essa abordagem também está fora do currículo da formação de professores, que, assim como os próprios formadores, muitas vezes desconhecem caminhos pedagógicos trilháveis sob a orientação das teorias acadêmicas. Infelizmente, ainda somos surpreendidos com didatizações pouco produtivas com base em conhecimentos científicos produzidos mais recentemente em resposta à abordagem prescritivista da tradição do ensino de língua portuguesa nas escolas básicas (Kleiman, 2014; Silva, 2012a; 2009). Não me restam dúvidas de que práticas colaborativas entre as instituições de ensino focalizadas podem dirimir esse problema (Athayde et al., 2013; Mateus, 2011).

O desafio do ensino descontextualizado de ciências na escola básica enfrentado por pesquisas do letramento científico está muito próximo à demanda pela formação sustentável do professor de Língua Portuguesa, daí o fortalecimento de uma das teses trazidas nesta pesquisa: o paradigma dominante da ciência moderna atinge diretamente o currículo escolar disciplinarizado e fragmentado no ensino básico. Por outro lado, nem todos os conteúdos disciplinares são passíveis de aplicação imediata, embora possuam valores culturais que precisam ser explicitados, a exemplo da riqueza constitutiva do nosso diverso acervo literário, compreendendo a produção consagrada dos grandes escritores brasileiros e, também, os escritos frequentemente marginalizados pela escola, como a literatura de cordel e as letras de música originárias da expressão cultural das periferias brasileiras. Nos termos de Sousa (2007, p. 481), 
conteúdos científicos com valor cultural, quando contextualizados, passam a ter significados para os alunos. Ocorre que a forma descontextualizada como o ensino de ciências é praticado nas escolas faz com que muitos dos conceitos científicos se transformem em palavreados tomados como meros ornamentos culturais repetidos pelos alunos sem qualquer significação cultural.

Desenvolvidos no âmbito da linguística aplicada, os estudos do letramento do professor respondem, de alguma forma, à demanda de subversão do trabalho pedagógico descontextualizado em aulas de Língua Portuguesa. A superação desse desafio vai além da seleção ou contextualização de conteúdos disciplinares; requer uma tomada de atitude dos atores sociais envolvidos com a educação numa perspectiva mais profunda da dimensão contemporânea do ensino, que, nos termos de Kleiman (2014, p. 82),

diz respeito à flexibilidade e ao respeito pela cultura do outro para garantir a inserção tranquila do aluno nos novos modos de fazer sentido via escrita na sociedade tecnológica em que imagem e texto escrito imperam. Ser contemporâneo é ouvir o que o outro quer e aproveitar a flexibilidade de novos modos de ser e significar para propiciar as condições para que o aluno satisfaça seu desejo.

A autonomia do professor para lidar com as situações com as quais depara no local de trabalho, tentando se reinventar constantemente, corresponde ao que Lüdke e Boing (2012, p. 443), na ciência da educação, denominam mais genericamente de profissionalidade: "Capacidade de o professor intervir como agente ativo no processo de ensino-apredizagem, diz respeito ao saber fazer e ao saber interpretar o que acontece nesse processo". Essa profissionalidade pode ser fortalecida quando as próprias formas de apreensão do conhecimento pelo professor são respeitadas, mesmo quando distanciadas das formas de ação reconhecidas pela academia.

Construído ao longo deste texto, o paradigma transformador para a formação sustentável do professor está orientado pelas noções intercambiáveis de letramento científico, letramento acadêmico e letramento do professor, conforme representado na Figura 2.

Para a formação sustentável, a familiarização do professor com práticas de letramento científico pressupõe o discernimento do funcionamento dos paradigmas científicos em disputa na contemporaneidade. A conscientização desse contexto desfavorável ao professor pode despertá-lo a criar condições para o estabelecimento de mais pontos de contato entre as instituições de ensino focalizadas, evitando a reprodução inconsciente de vozes acadêmicas dominantes. Nessa perspectiva, além da compreensão da natureza científica e de aspectos sociocientíficos, a linguagem acadêmica traz novas práticas de escrita a serem apropriadas pelo professor.

Os estudos do letramento acadêmico que usualmente focalizam crenças sobre a escrita do aluno ingresso na universidade se contrapõem ao discurso da crise da escrita supostamente provocada pela escola básica (Fiad, 2011; Fischer, 2008). $\mathrm{O}$ aluno do ensino básico é preparado para responder às práticas escolares de escrita, possibilitando sua travessia para o mercado de trabalho ou para a universidade, ainda 
que, ao ingressar em tais instituições, o egresso da escola básica seja surpreendido com demandas de letramento não familiares.

Assim como esse aluno, o professor ingresso no MP está inserido em práticas de escrita não legitimadas pela academia, por onde ele parece ter passado muito rapidamente durante a licenciatura. Porém, conforme afirmado por Fiad (2011, p. 360), ao investigar dizeres de alunos universitários sobre a própria escrita, "não é mais possível dizer que os estudantes [e também os professores] não sabem escrever de modo genérico e absoluto". O letramento acadêmico é a "fluência em formas particulares de pensar, ser, fazer, ler e escrever peculiares" ao contexto universitário (Fischer, 2008, p. 180), existindo outros letramentos fora desse contexto.

Pelo fato de o professor permanecer boa parte do tempo envolvido com atividades profissionais, as práticas escolares de escrita configuram-se como a zona de conforto dele. No esforço de legitimar o letramento desse profissional, Kleiman (2001, p. 43, grifos do original) defende que esse letramento deve ser analisado "da perspectiva das práticas de leitura e de escrita para o trabalho e no contexto do trabalho, levando em consideração, portanto, exigências e capacidades de comunicação efetivamente requeridas para ensinar".

A partir do momento em que a pesquisa científica encontra o professor, outras práticas de letramento acadêmico são demandadas. O professor depara com outros desafios a serem superados no complexo contexto profissional. A leitura de textos densamente teóricos, em língua materna ou estrangeira, ilustra apenas um desafio para o professor e formador, além da produção escrita de gêneros acadêmicos revisitados ou, até mesmo, então desconhecidos, como a dissertação,

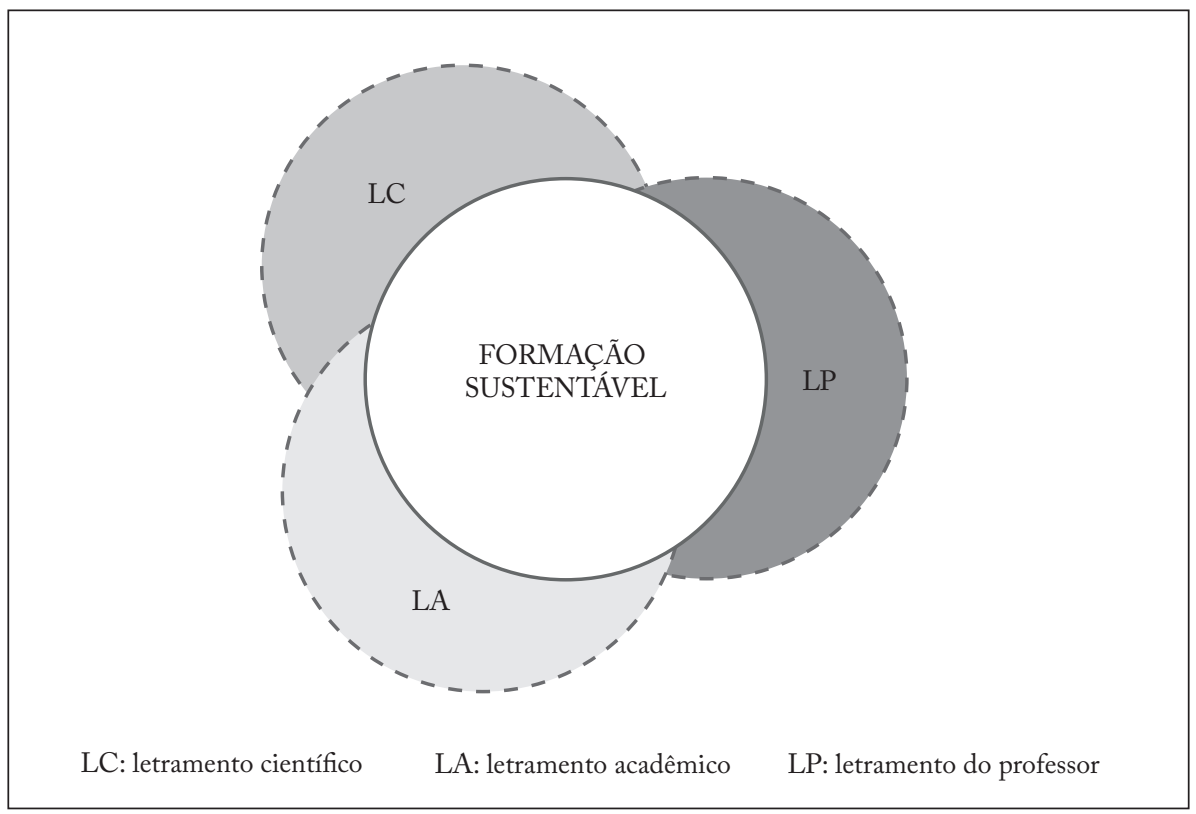

Figura 2 - Formação sustentável do professor. 
a ser elaborada como trabalho investigativo final, sobre a qual nos detemos mais diretamente na seção seguinte.

\section{VOZES EM CONFLITO: LETRAMENTOS EM CONSTRUÇÃO}

Provavelmente, a dissertação de mestrado não seja o produto final mais relevante ao mestrado para professores. Na universidade, por um lado, esse gênero pode contribuir para a reprodução do modelo de pesquisa da pós-graduação acadêmica. Por outro lado, a pesquisa-ação, aqui compreendida, nos termos de Zeichner e Diniz-Pereira (2005, p. 65), como uma "pesquisa sistemática feita por profissionais sobre as suas próprias práticas”, pode privilegiar vozes e anseios docentes numa escrita acadêmica marcada pela particularidade da reflexão sobre a prática profissional.

Referimo-nos à pesquisa-ação como tipo privilegiado de investigação no MP pela nossa própria experiência enquanto formadores revelar a relevância desse tipo de pesquisa para a produção de respostas às demandas do local de trabalho docente. No contexto internacional, Zeichner e Diniz-Pereira (2005, p. 64) procuram "reforçar os laços da pesquisa-ação com as lutas mais amplas por justiça social, econômica e política em todo o mundo". Ainda nos termos dos autores, destacamos:

Por um lado, o movimento da pesquisa-ação significou um reconhecimento de que os profissionais produzem teorias que os ajudam a tomar decisões no contexto prático. Por outro lado, esse movimento internacional também pode ser entendido como uma reação contra a visão dos profissionais como meros técnicos que apenas fazem o que os outros, fora da esfera da prática, desejam que eles façam e como uma rejeição às reformas "de cima para baixo" que concebem os profissionais apenas como participantes passivos (Zeichner; Diniz-Pereira, 2005, p. 66).

Nas subseções adiante, exemplificamos a disputa de forças em torno das práticas de letramento acadêmico construídas por meio do processo de reescrita de um projeto de dissertação posteriormente apresentado para exame de qualificação no ProfLetras ${ }^{7}$. A preparação do texto para qualificação aconteceu simultaneamente à implementação da pesquisa-ação pela professora-pesquisadora numa turma do 3. ${ }^{\circ}$ ano com alunos ainda em fase de alfabetização. As aulas para desenvolvimento da pesquisa foram cedidas pela professora alfabetizadora responsável pela turma,

7 No ProfLetras, o aluno precisa qualificar o projeto de pesquisa ao final do primeiro semestre letivo do curso, não havendo outro exame de qualificação da dissertação produzida. Fica a critério do orientador e do aluno a apresentação de um texto mais extenso para a qualificação, desde que não resulte em atraso do prazo estipulado. Essa exigência parece valorizar a atividade de preparação da pesquisa, diferentemente do mestrado acadêmico, em que a qualificação de dissertação acontece no momento avançado do curso, próximo à defesa de dissertação. Nesse último caso, a valorização incide sobre os resultados da pesquisa e sobre a forma como estes são apresentados. 
cujo papel desempenhado na pesquisa parece não ter ultrapassado o de espectadora, um lapso por nós admitido.

O desenvolvimento da pesquisa-ação na turma de outra professora justifica-se pelo fato de a responsável pela pesquisa permanecer apenas no quadro de formadores de professores na Secretaria de Educação, deixando as aulas de Língua Portuguesa em turmas do $6 .^{\circ}$ ano para conciliar o trabalho com as aulas do MP. Isso evidencia que o MP para professor em serviço é um caso superespecial. O modelo de funcionamento do curso ainda dificulta a conciliação da dupla atividade de estudo e de trabalho pelo professor, que não consegue afastamento do serviço público para capacitação profissional ${ }^{8}$.

Nas subseções seguintes, reproduzimos, no primeiro momento, dois exemplos de apropriação de vozes acadêmicas pela professora-pesquisadora, que, ao reingressar na universidade, responsabiliza colegas de trabalho por problemas existentes na escola básica (corresponde ao movimento representado pela letra B da Figura 1). No segundo momento, reproduzimos outros dois exemplos para ilustrar a construção de práticas de letramento científico no desenvolvimento da pesquisa-ação. Esses últimos revelam o apagamento da professora em atividade na escola, durante a pesquisa-ação realizada em sua sala de aula.

Todos os exemplos são compostos de três partes consecutivas: versão preliminar do excerto focalizado; orientação para reescrita; e versão para qualificação. Os trechos sublinhados correspondem à passagem textual destacada pelo formador ao apresentar orientação para reescrita utilizando a ferramenta de correção do Word. Neste artigo, utilizamos o itálico para destacar elementos linguísticos sinalizadores das vozes ou dos discursos propagados. Os exemplos também são úteis para mostrar a importância da interação pela escrita entre o professor e o formador no processo de formação, que se deseja sustentável.

\section{ALINHAMENTO DE VOZES: ESCOLA E UNIVERSIDADE}

Ao contextualizar o histórico de formação continuada na rede de ensino, especialmente das alfabetizadoras, a professora-pesquisadora demonstrou insistir em se manter na posição de formadora comprometida com a valorização da política oficial de formação, sem desconfiança ou manifestação de posicionamento mais crítico diante dos programas de formação. Desconsiderou a complexidade característica dos desafios enfrentados diariamente por ela mesma e pelas colegas alfabetizadoras, como se a tomada de consciência por elas fosse o suficiente para a transformação do ensino da língua materna.

Para as alfabetizadoras, seria empoderadora a valorização, por exemplo, da própria história de superação via escolarização, apesar das limitações deixadas pelas licenciaturas academicistas. Conforme esclarecido por Kleiman (2001, p. 42), o diploma obtido por elas "é resultado, muitas vezes, do esforço coletivo do grupo

8 Quase ao final do primeiro ano letivo do MP, a professora focalizada conseguiu o completo afastamento das atividades profissionais, assim como outras colegas de turma que já tinham se licenciado com mais facilidade. 
familiar em busca da ascensão social via escola”, mas, infelizmente, elas não se veem "nem são percebidas pelos demais (por exemplo, por nós, da academia) como membros legítimos de grupos letrados".

No Exemplo 1, a orientação para reescrita incide sobre a passagem textual em que "muitos profissionais da educação" são caracterizados pela reprodução de um modelo de "educação do passado", não respondendo às demandas da contemporaneidade, apesar do investimento público na educação. A orientação para reescrita parece ser utilizada para sensibilizar a professora-pesquisadora para outros aspectos influenciadores da prática do magistério, porém a reflexão apresentada não é complexificada. A resposta à orientação para reescrita foi a exclusão da passagem textual destacada.

\section{Exemplo 1}

\section{VERSÃO PRELIMINAR}

O governo federal tem investido em formações continuadas, com a finalidade de melhorar a prática pedagógica de muitos profissionais da educação que ainda não se deram conta que não dá mais para viver e trabalhar o agora, engajado numa educação do passado. É preciso assumir novos desafios, conhecer e compreender o que reza as novas diretrizes para a educação, em especial ao que se refere às práticas de leitura e escrita no contexto escolar atual.

\section{ORIENTAÇÃO PARA REESCRITA}

Essa fala parece arrogante. O problema é só professor acordar? Realmente estão dormindo?

\section{VERSÃO QUALIFICAÇÃO}

O governo federal tem investido em formações continuadas, com a finalidade de melhorar a prática pedagógica de muitos profissionais da educação. É preciso assumir novos desafios, conhecer e compreender o que reza as novas diretrizes para a educação, em especial ao que se refere às práticas de leitura e escrita no contexto escolar atual.

\section{Exemplo 2}

\section{VERSÃO PRELIMINAR}

O governo tem disponibilizado para escolas e professores do [Pacto Nacional pela Alfabetização na Idade Certa] PNAIC: jogos de alfabetização e de matemática, obras complementares: livros paradidáticos e de literatura infantil, tem fornecido material didático para o professor realizar leituras reflexivas sobre sua prática, propiciando assim para uma melhor preparação e dando maiores suportes para o trabalho em sala de aula. No entanto, toda essa mobilização não será suficiente se o professor não assumir o seu compromisso com o fazer pedagógico.

\section{ORIENTAÇÃO PARA REESCRITA}

Então está tudo perfeito, o problema é só o professor. Coloque-se no lugar do professor. Desça da posição de formadora.

\section{VERSÃO QUALIFICAÇÃO}

O governo tem disponibilizado para escolas e professores do PNAIC: jogos de alfabetização e de matemática, obras complementares: livros paradidáticos e de literatura infantil, tem fornecido material didático para o professor realizar leituras reflexivas sobre sua prática, propiciando assim uma melhor preparação e dando maiores suportes para o trabalho em sala de aula. No entanto, toda essa mobilização não será suficiente se todos os envolvidos neste processo não derem sua contribuição para o ensino (diretores, coordenadores pedagógicos, orientadores educacionais, professores alfabetizadores, família e o próprio aluno). 
$\mathrm{Na}$ versão textual reescrita, a cobrança sobre os profissionais da educação permanece ("É preciso assumir novos desafios..."). Continuam a ser representados como profissionais que precisam ou devem assumir orientações externas.

Infelizmente, há muitas pesquisas desenvolvidas em sala de aula com críticas que desmerecem o desempenho do professor, especialmente quando o responsável pela pesquisa se apropria de vozes preconceituosas originárias da própria academia. Essa situação distancia-se do risco inevitável assumido pelo professor ao autorizar registros de suas aulas para pesquisas científicas que, por um lado, inevitavelmente, podem gerar análises ou comparações que minimizam o trabalho do professor. E, por outro lado, geram resultados para melhorar as "condições de trabalho, através da implementação de melhores programas de formação e educação continuada, por exemplo"(Kleiman, 2001, p. 50).

\section{Exemplo 4}

\section{VERSÃO PRELIMINAR}

O período de geração dos dados nem sempre acontece de forma linear, pois existem aulas gratificantes, de alta relevância, que tudo sai dentro daquilo que planejamos, mas também tem momentos de muitas dificuldades, quando os colaboradores da pesquisa em lócus não contribuem ou deixam de contribuir como processo, dificultando as ações, como interromper durante as gravações, não disponibilizar com presteza os recursos de mídia da escola, como data show, caixa de som etc. Esses momentos são desgastantes.

\section{ORIENTAÇÃO PARA REESCRITA}

Tudo é dado, não existe alta relevância.

Cuidado com a forma que se expressa: parece que há um teatro ou cena planejada. As gravações não são interrompidas, pois tudo é gravado espontaneamente, os dados são gerados naturalmente.

\section{VERSÃO QUALIFICAÇÃO}

O período de geração dos dados nem sempre acontece de forma linear, pois existem circunstâncias que corroboram para que, muitas vezes, aquilo que havia sido planejado não saia como o esperado. Estes são alguns dos momentos em que o intempestivo interfere no bom andamento da aula, como, por exemplo: a tomada não funciona, o cabo do data show não funciona, a máquina fotográfica descarrega etc.

\section{Exemplo 3}

\section{VERSÃO PRELIMINAR}

Durante os trabalhos realizados com os alunos, tem tido momentos de suma importância durante as aulas e que solicitei à professora participante que filmasse as interações das crianças durante uma construção conjunta do texto e a mesma filmou abacaxis que estavam fixados na parede e sucatas que estavam sobre um balcão na sala de aula.

\section{ORIENTAÇÃO PARA REESCRITA}

O que isso significa? Veja meu texto de 2009 na Revista Brasileira de [Linguística Aplicada] LA.

\section{VERSÃO QUALIFICAÇÃO}

Durante os trabalhos realizados com os alunos, muitos têm sido os momentos de relevância.

Poderiam ter sido registradas através de filmagens as inferências significativas proferidas pelos alunos.

No entanto, em alguns momentos primordiais em que solicitei a participação da professora para

filmar as contribuições dos alunos em relação a uma construção conjunta do texto, a mesma

filmou elementos da sala que não eram úteis para a pesquisa, como imagens de abacaxis que estavam

fixados na parede e sucatas que estavam sobre um balcão na sala de aula. Deixou de registrar

o primordial, a imagem da criança dando sua contribuição para a produção do texto coletivo. 
No Exemplo 2, o parágrafo também é iniciado com a explicitação de supostos benefícios trazidos para a educação por políticas oficiais. Como arremate, o professor é caracterizado pela ausência ou negação (não) do compromisso profissional. Em outras palavras, a solução para os desafios do magistério parece estar exclusivamente nas mãos do professor, quando a própria professora-pesquisadora demonstra dificuldade na elaboração de uma proposta interventiva orientada pela pesquisa-ação, mesmo utilizando diretamente conhecimentos acadêmicos compartilhados no MP. Essa dificuldade é enfrentada por qualquer idealista interessado em elaborar alguma proposta didática em contraposição à prática escolar ou ao paradigma educacional dominante.

$\mathrm{Na}$ orientação para reescrita, o formador autorrepresenta-se de forma mais enérgica. Abandona a asserção e as perguntas modalizadas a exemplo das utilizadas no Exemplo 1 ("Essa fala parece arrogante. O problema é só professor acordar? Realmente estão dormindo?”). No Exemplo 2, o formador assume asserções mais firmes e irônicas ("Então está tudo perfeito, o problema é só o professor") e comandos incisivos ("Coloque-se no lugar do professor. Desça da posição de formadora"), todos utilizados em letras maiúsculas, o que, considerando a linguagem da internet, contribui para a intensificação do conteúdo enunciado.

$\mathrm{Na}$ versão reescrita, a reflexão realizada é complexificada um pouco. A passagem textual destacada não é simplesmente apagada, conforme evidenciamos no Exemplo 1. Além da substituição da expressão nominal "o professor" por "todos os envolvidos neste processo", são enumerados entre parênteses alguns atores sociais com os quais o professor poderia compartilhar a responsabilidade pela transformação do ensino ("diretores, coordenadores pedagógicos, orientadores educacionais, professores alfabetizadores, família e o próprio aluno”). É relevante notar que a própria professora-pesquisadora, formadora na rede de ensino focalizada, não se insere entre esses atores sociais.

\section{VOZES DESLOCADAS DA PESQUISA}

Tanto no texto de qualificação como nos encontros para orientação e estudo dos quais participavam outras mestrandas, a professora-pesquisadora ressaltava insatisfação com a falta de entrosamento da professora da turma na pesquisa-ação. A função de formadora exercida pela primeira é um elemento considerado no esforço para compreensão da relação interpessoal instaurada na intervenção. Assim como acontece em outras situações em que o provável diálogo entre universidade e escola é escamoteado, como nos estágios supervisionados obrigatórios das licenciaturas (Silva, 2014; 2012b), quando professores cedem suas aulas aos estagiários, a professora utiliza o horário de aula disponível para realizar atividades profissionais pendentes, a exemplo do planejamento de aulas e da elaboração e correção de avaliações.

Outras duas professoras-pesquisadoras demonstram semelhante insatisfação, ao desenvolverem uma pesquisa-ação em parceria, por conta da proximidade dos objetos de investigação por elas construídos. Porém admitem terem contornado parcialmente a situação pela insistência e pelo traquejo exercidos por uma delas para envolver a professora da escola na intervenção. Algumas notas de campo com 
impressões da professora sobre as aulas ministradas pela dupla, por exemplo, foram solicitadas na tentativa de envolvê-la como participante da intervenção.

A observação crítica das intervenções realizadas por professoras-pesquisadoras sob nossa orientação revelou que a valorização da pesquisa-ação desenvolvida pelo professor não é suficiente para construirmos um terceiro espaço significativamente colaborativo entre as instituições de ensino representadas, especialmente pelo fato de as professoras-pesquisadoras ficarem impossibilitadas de fazer intervenções em suas próprias turmas. As professoras das escolas colaboradoras foram deslocadas, não participando efetivamente do planejamento das intervenções. De alguma forma, continuamos reproduzindo um campo de forças semelhante ao representado pela letra A na Figura 1.

No Exemplo 3, reproduzimos um excerto da metodologia da pesquisa. O gesto de filmagem pela alfabetizadora dos recursos didáticos fixados nas paredes e de materiais produzidos em suas próprias aulas foi deslegitimado pela professora-pesquisadora ("ela filmou abacaxis que estavam fixados na parede e sucatas que estavam sobre um balcão na sala de aula"). Ela esperava o registro de situações de ensino que evidenciassem os bons resultados produzidos pela intervenção em curso ("as inferências significativas proferidas pelos alunos. Deixou de registrar o primordial, a imagem da criança dando sua contribuição para a produção do texto coletivo").

A orientação para reescrita pelo questionamento do significado do gesto da alfabetizadora, seguida pela sugestão de artigo sobre o ambiente de letramento escolar usualmente construído na escola ("O que isso significa? Veja meu texto de 2009 na Revista Brasileira de $L A A^{\prime}$ ), gerou reelaboração diferente da compreensão desejada pelo formador. A professora-pesquisadora insistiu em afirmar que as gravações "não eram úteis para a pesquisa”, porém não conseguiu se colocar no lugar da professora, nem compreendeu, no momento, a existência de interesses diferenciados em disputa durante a intervenção. A disponibilização de uma filmadora para uso espontêneo do professor no contexto escolar pode se configurar como uma produtiva estratégia de geração de dados para a pesquisa.

Os dados evidenciam que a familiarização da professora-pesquisadora com práticas de letramento científico acontece no processo de produção da pesquisa. Realizadas previamente, as leituras acadêmicas não são suficientes para a construção de conhecimentos práticos que efetivamente orientem as atividades de pesquisa. O Exemplo 4 também ilustra essa apropriação de práticas de letramento acadêmico.

$\mathrm{Na}$ versão preliminar do Exemplo 4, a não linearidade na produção dos dados de pesquisa é apresentada como uma descoberta pela professora-pesquisadora ("nem sempre acontece de forma linear"). Ao mesmo tempo, os denominados colaboradores da pesquisa são representados exatamente pela falta de colaboração para o tranquilo ou ininterrupto desenvolvimento da intervenção ("os colaboradores da pesquisa em lócus não contribuem ou deixam de contribuir com o processo"). Provavelmente, o comportamento desses atores sociais é o mesmo demonstrado nas atividades cotidianas da escola, o que poderia ser reconhecido pela professora-pesquisadora. No entanto, ela parece cobrar um comprometimento diferenciado durante a intervenção desenvolvida, demandando, de alguma maneira, algum conhecimento sobre a prática de pesquisa científica. 
Quando comparada com os exemplos reproduzidos previamente, a orientação para reescrita do Exemplo 4 é mais extensa, apresentando mais conteúdo informacional. $\mathrm{O}$ formador evita questionamentos ou modalizações e explica, energicamente, o funcionamento natural da atividade científica de geração de dados. Na versão reescrita, é apagado o enunciado com cobranças sobre os indivíduos então caracterizados como colaboradores da pesquisa-ação, e o "intempestivo" é assumido como constitutivo da aula.

\section{CONSIDERAÇÕES FINAIS}

Numa perspectiva investigativa indisciplinar, esta revisão da literatura científica revelou que o MP foi concebido para responder às demandas descobertas do mercado de trabalho brasileiro, a exemplo dos desafios contemporâneos do ensino básico. Esse fato é provocado pela oferta de cursos de graduação e de pós-graduação acadêmica marcadamente teóricos, que pouco contribuem para a produção compartilhada de conhecimento, de maneira a impactar amplamente a sociedade.

Nesse sentido, o sucesso do ProfLetras depende muito da observância de práticas científicas e pedagógicas distanciadas do paradigma dominante do conhecimento. $\mathrm{Na}$ universidade, as demandas trazidas pelo professor precisam ser valorizadas e orientar o trabalho coletivo de produção de inovação para o ensino de língua portuguesa na escola básica. Esse intercâmbio de experiências entre as instituições representadas, informado especialmente por conhecimentos práticos, também pode fortalecer o repertório do formador, alcançando até mesmo o trabalho de formação inicial na licenciatura.

$\mathrm{O}$ reingresso do professor na universidade requer sua familiarização com diversos letramentos (científico, acadêmico e do professor), os quais costumam estar distanciados dos usos familiares da escrita necessários no cotidiano da escola básica. São apropriados paulatinamente pelo professor quando depara com efetivas situações interativas que requerem novos letramentos, como revelaram nossas análises exemplificadas do processo de (re)escrita, e não simplesmente pela leitura orientada da literatura científica. As diferentes concepções de letramento trazidas neste estudo precisam ser revisitadas por pesquisas científicas considerando o contexto diferenciado da formação sustentável do professor no MP.

Finalmente, precisamos admitir que, provavelmente, ainda estamos influenciados pelo paradigma científico dominante ao parecermos insistir na criação de produtos como resultados das investigações realizadas pelo e para o professor, prática característica das pesquisas realizadas nas ciências duras. No contexto do ProfLetras, também precisamos reconhecer que a experiência vivenciada pelo professor com a prática de pesquisa em e sobre as aulas de Língua Portuguesa pode torná-lo um profissional mais autônomo no local de trabalho. Esse talvez seja o resultado mais impactante para a sociedade?

9 Agradecemos a nossas orientandas do ProfLetras a presteza em realizar uma leitura crítica deste artigo. A responsabilidade pelo manuscrito, porém, é completamente nossa. 


\section{REFERÊNCIAS}

Athayde, Simone; Bartels, Wendy-Lin; Buschbacher, Robert; Rosa, Rosane Duarte. Aprendizagem colaborativa, transdisciplinaridade e gestão socioambiental na Amazônia: abordagens para a construção de conhecimento entre academia e sociedade. Revista Brasileira de Pós-Graduação, 2013, v. 10, n. 21, p. 729-756.

Barton, David; Papen, Uta. The Anthropology of Writing: Understanding TextuallyMediated Worlds. London: Continuum, 2010.

Bourdieu, Pierre. O poder simbólico. 7a ed. Rio de Janeiro: Bertrand Brasil, 2004. . Razôes práticas: sobre a teoria da ação. 3a ed. São Paulo: Papirus, 2001.

Castro, Cláudio de M. A hora do mestrado profissional. Revista Brasileira de PósGraduação, v. 2, n. 4, p. 16-23, 2005.

Edital n. ${ }^{\circ}$ 001/2015 - Exame Nacional de Acesso ao Mestrado Profissional em Letras. Disponível em: <http://www.comperve.ufrn.br/conteudo/posgraduacao/ profletras/201501/documentos/edital_retificado_20150703.pdf> Acesso em: 26 jul. 2015. FIAD, Raquel S. A escrita na universidade. Revista da ABRALIN, n. especial, 2a parte, p. 357-369, 2011.

Fischer, Adriana. Letramento acadêmico: uma perspectiva portuguesa. Acta Scientiarum. Language and Culture, v. 30, n. 2, p. 177-187, 2008.

Kleiman, Angela B. Letramento na contemporaneidade. Bakbtiniana, São Paulo, v. 9, n. 2, 2014.

.Letramento e formação do professor: quais as práticas e exigências no local de trabalho. In: Kleiman, Angela B. A formação do professor: perspectivas da Linguística Aplicada. Campinas: Mercado de Letras, 2001. p. 39-68.

Kleiman, Angela B.; Dos Santos, Cosme B. Estudos de letramento do professor: percursos metodológicos. In: Gonçalves, Adair V.; Silva, Wagner R.; Góis, Marco L. de S. (Orgs.). Visibilizar a Linguística Aplicada: abordagens teóricas e metodológicas. Campinas: Pontes, 2014. p. 183-204.

Latour, Bruno. Jamais fomos modernos. Tradução de Carlos Irineu da Costa. Rio de Janeiro: Editora 34, 1994.

Lüdke, Menga; Boing, Luiz A. Do trabalho à formação de professores. Cadernos de pesquisa, v. 42, n. 146, p. 428-451, 2012.

Mateus, Elaine. Ética como prática social de cuidado com o outro: implicações para o trabalho colaborativo. In: Magalhães, Maria C. C.; Fidalgo, Sueli S. (Orgs.). Questões de método e de linguagem na formação docente. Campinas: Mercado de Letras, 2011. p.187-209.

Nóvoa, António. Nada substitui o bom professor. In: Faro, J. S.; Gutierre, Priscilla (Eds.). Desafios do trabalho do professor no mundo contemporâneo (livreto). São Paulo: SINPRO-SP, 2007. Disponível em: <http://www.sinpro.org.br/noticias. asp?id_noticia=639 >. Acesso em: 20 jun. 2013.

Quelhas, Osvaldo L. G.; Faria Filho, José R.; França, Sérgio L. B. O mestrado profissional no contexto do sistema de pós-graduação brasileira. Revista Brasileira de Pós-Graduação, v. 2, n. 4, p. 8-15, 2005. 
Rabelo, Laudemira S. et al. A experiência do Prodema na pós-graduação brasileira: ciência para sustentabilidade na UFC. Revista Brasileira de Pós-Graduação, v. 10, n. 21, p. 633-660, 2013.

Rattner, Henrique. Sustentabilidade: uma visão humanística. Ambiente E̊ Sociedade, n. 5, p. 233-240, 1999.

Ribeiro, Renato J. O mestrado profissional na política atual da CAPES. Revista Brasileira de Pós-Graduação, v. 2, n. 4, p. 97-104, 2005.

SAntos, Wildson L.P. Educação científica na perspectiva de letramento como prática social: funções, princípios e desafios. Revista Brasileira de Educação, v. 12, n. 36, p. 474550, 2007.

Silva, Wagner R. Reflexão pela escrita no estágio supervisionado da licenciatura: pesquisa em Linguística Aplicada. Campinas: Pontes Editores, 2014.

. Gêneros textuais em aulas de Língua Portuguesa no Ensino Médio brasileiro. Linguagem E Ensino, v. 15, n. 2, p. 387-418, 2012a.

. Letramento do professor em formação inicial: interdisciplinaridade no estágio supervisionado da licenciatura. Campinas: Pontes Editores, 2012b.

. Seleção textual no ensino interdisciplinar por projeto. Revista Brasileira de Linguistica Aplicada, v. 9, n. 1, p. 17-39, 2009.

Sousa Santos, Boaventura. Para além do pensamento abissal: das linhas globais a uma ecologia de saberes. Novos Estudos, n. 79, p. 71-94, 2007.

. Um discurso sobre as ciências. $7^{\mathrm{a}}$ ed. Porto: Edições Afrontamento, 1995.

Zeichner, Kenneth.; Diniz-Pereira, Júlio E. Pesquisa dos educadores e formação docente voltada para a transformação social. Cadernos de pesquisa, v. 35, n. 125, p. 6380, 2005 .

Zeichner, Kenneth; Payne, Katherina A.; Brayko, Kate. Democratizing teacher education. Journal of Teacher Education, v. 66, n. 2, p. 122-135, 2014. Disponível em: $<$ https://www.researchgate.net/publication/272381302_Democratizing_Teacher_ Education>. Acesso em: 10 mar. 2015.

\section{SOBRE O AUTOR}

Wagner Rodrigues Silva é doutor em Linguística Aplicada pela Universidade Estadual de Campinas (UNICAMP). Professor da Universidade Federal do Tocantins (UFT).

E-mail:wagnersilva@uft.edu.br

Recebido em $1 .^{\circ}$ de abril de 2015

Aprovado em 27 de julbo de 2015 